\title{
Causal Linkage between Inflation and Unemployment: An evidence from the Selected MENA Countries
}

\author{
Tarek Kacemi ${ }^{1}$, Sallahuddin Hassan ${ }^{2}$ \\ ${ }^{1}$ PhD Scholar, School of Economics, Finance \& Banking, Universiti Utara Malaysia \\ ${ }^{2}$ Associate Professor, School of Economics, Finance \& Banking, Universiti Utara Malaysia \\ Email: tarek.king39@gmail.com
}

\begin{abstract}
The current study measures the causal association between inflation and unemployment employing Phillips Curve approach from 1990 until 2016 for selected MENA countries. Granger causality and the heterogeneous causality methods for Panel are employed by this study as proposed by Dumitrescu and Hurlin. This causality test has an advantage over the panel Granger causality as it considers two dimensions of heterogeneity. The finding revealed a unidirectional causality between unemployment and inflation with Panel Dumitrescu and Hurlin Granger causality but not in the panel Granger causality test. Therefore, the governments should choose to stabilize inflation rate or reduce unemployment rate.

Keywords: Inflation, Unemployment, Granger Causality, Dumitrescu Hurlin Causality, MENA.
\end{abstract}

\section{Introduction}

Inflation and unemployment are two major concerns of every economy because the primary goal of them is to achieve a high economic growth with full employment and low inflation. However, mentioned by Fischer and Modigliani (1978), inflation has become a well-entrenched phenomenon in many countries. It imposes considerable economic costs because it is usually considered detrimental to economic growth and development when it exceeds some acceptable limits. Unemployment has also always been a significant issue for many economists in different economies. It has become an even bigger problem in the time of recession.

The adverse linkage amid inflation rate and the unemployment originated the concept of a perpetual and smooth relationship between these two variables. Cashell (2004) asserted that "policymakers could 'buy' (at least in the short run) a lower rate of unemployment at the cost of a higher rate of inflation". As a matter of fact, Phillips theorized that money wage changes are explained by the unemployment rate, where it also be assumed that causality 
could likewise run the other way, particularly when researchers infer the rate of money wage changes to the inflation rate. One way to interpret this supposed trade-off, which is the foundation of this study, is that by tolerating a higher rate of inflation a lower level of unemployment could be had.

The economic argument domestically goes as follows: a growing economy enhances level of output, increase in the demand for the labor and hence surge in employment level. Nevertheless, inflation also surges in a rapidly growing economy. In this case, inflation does not bring changes in employment as it is a result of robust economic growth, relatively higher inflation and it therefore has to be "tolerated" to attain a higher employment rate. Though as argued, if economic growth to be reduced to mitigate the inflationary pressures, this would be detrimental to the employment creation and additionally to the economic growth (Vermeulen, 2015).

The objective of this paper is to examine the causal association between inflation and the unemployment in selected MENA economies over 1990-2016 period. This study compares the standard homogenous panel assumption in Granger causality and the Dumitrescu-Hurlin panel causality that well-verse for its heterogeneity analysis. In precise, Dumitrescu-Hurlin panel causality (2012) had an advantage over the standard Granger causality as it hypothesizes causality running from an individual to another subgroup of individuals. The standard Granger (1969) causality hypothesizes intercepts and the slope coefficients to be same.

In the remaining article, section 2 discusses the literature review on the nexus and causal relationships between inflation and unemployment. Section 3 continues below with the methodology and followed by Section with the discussion of the results, and last but not least, Section 5 the concluding remarks.

\section{Literature Review}

This paper reviews the studies on causality test for inflation and unemployment. The normal results of test explain inter variables causal one-way and two-way causality. Umoru and Anyiwe (2013) concluded that there exists a two-way causality between the inflation rate and unemployment with Engle-Granger test in Nigeria between 1985-2012. On the other hand, Kogid, Asid, Mulok, Lily, and Loganathan (2012) found a unidirectional causal relationship from rate of inflation to the unemployment with the Toda-Yamamoto method in Malaysia during 1975-2007. Likewise, the study of Umaru and Zubairu (2012) discovered the 
direction of causality amongst inflation rate and the unemployment was ascertained used the Granger causality in Nigeria from 1977-2009.

Also, Siyan, Adegoriola, and Adolphus (2016) indicated that there exists a one-way causal linkage between the rate of unemployment and the corresponding inflation in Nigeria during 1980 to 2014. Bildirici and Özaksoy (2016) analysed Post-Keynesian Philips Curve by employing the non-linear Autoregressive Distributed Lag (ARDL) approach and the nonlinear Granger causality technique covering the 1957 to 2015 period, in Canada. They found that Canada exhibits bidirectional causal linkage between inflation and unemployment, which denotes that the economy contains flexible labour market. Furthermore, the result of causality test of Sa'idu and Muhammad (2015) concludes that inflation is not granger caused by the unemployment; however, inflation Granger causes the unemployment. Hence, the outcomes indicate a one-way causal relationship flowing from the inflation. Moreover, Škare and Caporale (2014) examined the short-run and long-run association between employment growth and rate of inflation by using the panel co-integration and causality tests in case of 119 countries over the 1970 by 2010 period. They found evidence of positive Granger causality.

Furthermore, Furuoka, Munir and Harvey (2013) revealed the one-way causal linkage between rate of inflation and the unemployment in context of Philippines during the 19802010 period. In another study, Furuoka and Munir (2014) found existence unidirectional causality amid the unemployment rate and the inflation rate in Malaysia during 1973-2004 with and Granger causality. Moreover, Yelwa, David, and Awe (2015) reveal the existence of unidirectional causality between rate of inflation, unemployment and the economic growth in Nigeria over the 1987-2012 period. Dritsaki and Dritsaki (2013) examined the association between rate of inflation and unemployment in Greece over the $1980-2010$ periods, with Granger causality test. Their funding shows that there is a one-way causal inflation effect to unemployment.

As in MENA, the empirical study of the direction of causality were only conducted by few researchers like Özer and Özata (2016) and Abdulrahman, Sabil, and Mohamed (2016). These studies came with the different conclusion where the former study revealed the bidirectional causality between inflation and unemployment in Turkey during 2003-2016. Also, the sign of the causality is negative in Turkey. While the latter study indicating no causal association amongst the two variables in Sudan throughout the period of 1992-2015. Thus, the objective of this paper is a complement to the literature as it becomes necessary 
given that the inflation drives unemployment in some countries, while the opposite obtains in other countries.

Overall, though the application of econometric models and quantitative techniques on identifying the direction of the causality between inflation and unemployment is extensive globally, it remains limited in the case of MENA countries. This study will thus address the gap of limited study for the case of MENA countries and contribute both methodology and empirical implication.

\section{Methodology}

This study with a panel-data sets that covering the selected 9 MENA (Algeria, Egypt, Iran, Morocco, Saudi Arabia, Sudan, Turkey, and Tunisia) countries, over the period 19902016 using annual data from World Bank database to examine the causal nexus between inflation and unemployment.

The current empirical analysis relies on a functional relationship that can be expressed as shown in Equation [1]:

$$
I N F=f(U E M, E X R, G D P, P R, M S)
$$

Where the INF denotes inflation, UEM represents unemployment rate, EXR represents exchange rate, GDP is Gross Domestic Product growth rate, $P R$ as the population growth rate and $M S$ is money supply.

\section{A. Testing for Causality}

Causality is the idea arguing that the future is not capable of causing the past; however, the past is possibly can cause the future (Granger, 1988). According to Granger description of causality, $X_{t}$ causes $Y_{t}$, if $Y_{t}$ is capable to predict efficiently by employing the past values of $X_{t}$. Thus, if previous values $X_{t}$ considerably add to predicting $Y_{t}$ that moment, $X_{t}$ is believed to Grange causes $Y_{t}$. Conversely, causality running from the $Y$ to the $X$ may as well be explained as when previous values of $Y_{t}$ considerably donate to predicting $X_{t}$, at that moment $Y_{t}$ is supposed to Granger causes $X_{t}$. The Granger causality technique considers estimation of null hypothesis that does $Y_{t}$ is not caused by $X_{t}$ and vice versa. Equations [2] and Equation [3] are used in estimating causality:

$$
Y_{t}=\alpha_{0}+\sum_{i=1}^{n} \alpha_{1 i} Y_{t-1}+\sum_{i=1}^{n} \beta_{1 i} X_{t-1}+\varepsilon_{t}
$$




$$
X_{t}=\beta_{0}+\sum_{i=1}^{n} \alpha_{2 i} Y_{t-1}+\sum_{i=1}^{n} \beta_{2 i} X_{t-1}+\varepsilon_{t}
$$

Where the error term and the number of lagged variables are are presented by $n$. The null hypothesis $\left(H_{0}\right), Y_{t}$ is not Granger caused by $X_{t}$ is not accepted if $\beta_{1 i}$ are significant jointly. Similarly, the $H_{0}$ i.e. $X_{t}$ is not Granger caused by $Y_{t}$ is not accepted if $\alpha_{i s}$ are rejected jointly.

The Granger causality method that is proposed in this study is developed based on extension from Equation [2] and Equation [3] $H_{0}$ is represented by Equation [4] and Equation [5]:

$$
\begin{aligned}
\Delta I N F_{i t} & =\alpha_{1 j}+\sum_{k=1}^{q} \varphi_{11 i k} \Delta I N F_{i t-k}+\sum_{k=1}^{q} \varphi_{12 i k} \Delta U E M_{i t-k}+\sum_{k=1}^{q} \varphi_{13 i k} \Delta E X R_{i t-k}+\sum_{k=1}^{q} \varphi_{14 i k} \Delta P R_{i t-k}+\sum_{k=1}^{q} \varphi_{15 i k} \Delta M S_{i t-k} \\
& +\sum_{k=1}^{q} \varphi_{16 i k} \Delta G D P_{i t-k}+u_{1} i t
\end{aligned}
$$

$$
\begin{aligned}
\Delta U E M_{i t} & =\beta_{2 j}+\sum_{k=1}^{q} \varphi_{21 i k} \Delta I N F_{i t-k}+\sum_{k=1}^{q} \varphi_{22 i k} \Delta U E M_{i t-k}+\sum_{k=1}^{q} \varphi_{23 i k} \Delta E X R_{i t-k}+\sum_{k-1}^{q} \varphi_{14 i k} \Delta P R_{i t-k}+\sum_{k-1}^{q} \varphi_{25 i k} \Delta M S_{i t-k} \\
& +\sum_{k=1}^{q} \varphi_{26 i k} \Delta G D P_{i t-k}+u_{2 i t}
\end{aligned}
$$

Where $\Delta$ is used for first-difference operator; $q$ for the lag length, whereas $u$ indicates the serially uncorrelated disturbance term. The standard panel Granger causality developed by Granger (1969) is compatible with homogenous panels and considers all the intercept and the slope coefficients to be same. While in the discussion of the Hoaltz and Eakin (1988) study, he presented a study examining the "Homogeneous Non-Causality (HNC)" in contradiction of the "Homogeneous Causality (HC)." They have examined the null hypothesis that Granger causality does not exist amongst the variables linked to all the entities contrary to the alternative hypothesis considering a Granger causal association between the variables linked to the all entities.

The homogeneity postulation is an extremely stern postulation and it may direct to an acceptation that as if the causal association occurs in all the respective cross- sections, nevertheless, it exists in only a subgroup of the panel. In other words, this test of panel causality overlooks the heterogeneity amongst the individual elements. Nevertheless, crosssectional information considers heterogeneity across the individuals. 
The test proposed by Dumitrescu and Hurlin (2012) undertook the following issue through examining the "Homogeneus Non- Causality (HNC)" in contradiction of the "Heterogeneous Non-Causality (HENC)." In precise, HENC argues that there exists a causal linkage from one entity to other for a subcategory of entities. Dumitrescu and Hurlin propose the null hypothesis $\left(H_{0}: \beta_{i}=0, i=1, \ldots, N\right)$, in contrast to the existing alternative hypothesis according to which causal associations happens for at least one subgroup in the panel, $\left(H_{1}: \beta_{i}=0, i=1, \ldots, N_{1}\right) ;\left(\beta_{i} \neq 0, i=N_{1}+1, N_{1}+2, \ldots, N\right)$. Moreover, rejection of the null hypothesis , $N_{l}=0$ specifies that x Granger causes y for all $i$, whereas rejection of the null hypothesis with $N_{l}>0$ provides evidence that the regression model and the causal relations vary from one individual or the sample to another.

A Bivariate model provides the basis for the of Dumitrescu-Hurlin panel causality test. The system to be estimated can be written in Eq [6] \& Eq [7].

$$
\begin{aligned}
I N F_{i, t} & =\alpha_{i}+\sum_{k=1}^{k} \beta_{i}^{k} I N F_{i, t-k}+\sum_{k=1}^{k} \lambda_{i}^{k} U E M_{i, t-k}+\sum_{k=1}^{k} \varphi_{i}^{k} E X R_{i, t-1}+\sum_{k=1}^{k} \gamma_{i}^{k} P R_{i, t-1}+\sum_{k=1}^{k} \delta_{i}^{k} M S_{i, t-1} \\
& +\sum_{k=1}^{k} \mu_{i}^{k} G D P+\varepsilon_{i, t}
\end{aligned}
$$

$$
\begin{aligned}
U E M_{i, t} & =\alpha_{i}+\sum_{k=1}^{k} \beta_{i}^{k} U E M_{i, t-k}+\sum_{k=1}^{k} \lambda_{i}^{k} I N F_{i, t-k}+\sum_{k=1}^{k} \varphi_{i}^{k} E X R_{i, t-1}+\sum_{k=1}^{k} \gamma_{i}^{k} P R_{i, t-1}+\sum_{k=1}^{k} \delta_{i}^{k} M S_{i, t-1} \\
& +\sum_{k=1}^{k} \mu_{i}^{k} G D P+\varepsilon_{i, t}
\end{aligned}
$$

In the above equations, $\mathrm{K}$ indicates the lag length number, $\alpha$ is used for intercept, similarly, $\beta$ and $\lambda$ are used for the unknown slope coefficients. The outcomes obtained by the panel causality methods are sensitive with the lag length. In the current study, seven was taken as the maximum lag length for several reasons. First, by inserting the lagged values of the economic series, one can enhance the predictability of any other economic series. Second, the data used in this study uses yearly data and third due to the significance of the finding. In addition, Dumitrescu and Hurlin panel Granger test of causality is a beneficial technique assuming the cross-section dependence that is the objective of current investigation.

The Panel Granger test of causality (Dumitrescu and Hurlin) holds two benefits as compared to the popular causality test of Granger (1969), for instance, in addition to the fixed coefficient accounted in Granger (1969) test of causality, it assumes two dimensions of the heterogeneity and considers all coefficients to be diverse over the cross-sections. For this 
purpose, we employ pairwise Granger Causality Test and panel test of causality proposed by Dumitrescu and Hurlin (2012).

\section{Discussion}

The following segment aims to reveal the outcomes regarding the causality direction between inflation and unemployment in MENA countries.

Table 2: Pairwise Granger Test Result

\begin{tabular}{cccc}
\hline Null Hypothesis & F-Statistic & Prob. & Conclusion \\
\hline UEM does not Granger Cause INF & 0.565 & 0.784 & Zero causality \\
INF does not Granger Cause UEM & 0.329 & 0.940 & \\
\hline EXR does not Granger Cause INF & 1.326 & 0.241 & Zero causality \\
INF does not Granger Cause EXR & 0.696 & 0.675 & \\
\hline GDP does not Granger Cause INF & 1.569 & 0.148 & Zero causality \\
INF does not Granger Cause GDP & 0.510 & 0.826 & \\
\hline MS does not Granger Cause INF & 16.287 & $0.000^{*}$ & Unidirectional causality \\
INF does not Granger Cause MS & 0.542 & 0.802 & \\
\hline PR does not Granger Cause INF & 1.566 & 0.149 & Zero causality \\
INF does not Granger Cause PR & 0.773 & 0.611 & \\
\hline EXR does not Granger Cause UEM & 0.417 & 0.891 & Zero causality \\
UEM does not Granger Cause EXR & 0.973 & 0.453 & \\
\hline GDP does not Granger Cause UEM & 0.969 & 0.456 & Zero causality \\
UEM does not Granger Cause GDP & 1.121 & 0.352 & \\
\hline MS does not Granger Cause UEM & 0.131 & 0.996 & Zero causality \\
UEM does not Granger Cause MS & 0.960 & 0.463 & \\
\hline PR does not Granger Cause UEM & 3.647 & $0.001 *$ & Unidirectional causality \\
UEM does not Granger Cause PR & 0.652 & 0.713 & \\
\hline GDP does not Granger Cause EXR & 1.440 & 0.193 & Zero causality \\
EXR does not Granger Cause GDP & 0.891 & 0.515 & \\
\hline MS does not Granger Cause EXR & 0.843 & 0.553 & Zero causality \\
EXR does not Granger Cause MS & 1.240 & 0.284 & \\
\hline PR does not Granger Cause EXR & 0.683 & 0.687 & Zero causality \\
EXR does not Granger Cause PR & 0.368 & 0.920 & \\
\hline MS does not Granger Cause GDP & 0.734 & 0.643 & Zero causality \\
GDP does not Granger Cause MS & 0.920 & 0.492 & \\
\hline PR does not Granger Cause GDP & 1.871 & $0.077 *$ & Unidirectional causality \\
GDP does not Granger Cause PR & 0.922 & 0.491 & \\
\hline PR does not Granger Cause MS & 0.782 & 0.603 & Zero causality \\
MS does not Granger Cause PR & 0.155 & 0.993 & \\
\hline
\end{tabular}

Note: * represents 5 percent level of significance.

Table 2 shows that there is no indication of causality amongst inflation and unemployment in the Granger causality technique. The lack of evidence between these two variables may due the fixed coefficient that accounted in Granger causality test. 
Table 3: Pairwise Dumitrescu Hurlin Panel Causality Test

\begin{tabular}{|c|c|c|c|c|}
\hline Null Hypothesis & W-Stat. & $\begin{array}{l}\text { Zbar- } \\
\text { Stat. }\end{array}$ & Prob. & Conclusion \\
\hline UEM does not homogeneously cause INF & 26.559 & 2.266 & $0.0235^{*}$ & \\
\hline INF does not homogeneously cause UEM & 15.945 & 0.651 & 0.5151 & \\
\hline EXR does not homogeneously cause INF & 17.860 & 0.942 & 0.3461 & Zero causality \\
\hline INF does not homogeneously cause EXR & 8.427 & -0.493 & 0.6221 & \\
\hline GDP does not homogeneously cause INF & 19.628 & 1.211 & 0.226 & Zero causality \\
\hline INF does not homogeneously cause GDP & 21.981 & 1.569 & 0.117 & \\
\hline MS does not homogeneously cause INF & 35.917 & 3.689 & $0.000 *$ & Unidirectional \\
\hline INF does not homogeneously cause MS & 19.038 & 1.121 & 0.262 & causality \\
\hline PR does not homogeneously cause INF & 15.418 & 0.571 & 0.568 & Zero causality \\
\hline INF does not homogeneously cause PR & 13.728 & 0.314 & 0.754 & \\
\hline EXR does not homogeneously cause UEM & 14.925 & 0.496 & 0.620 & Unidirectional \\
\hline UEM does not homogeneously cause EXR & 53.739 & 6.400 & $0.000 *$ & \\
\hline GDP does not homogeneously cause UEM & 26.898 & 2.317 & 0.021 & Unidirectional \\
\hline UEM does not homogeneously cause GDP & 16.371 & 0.716 & 0.474 & causality \\
\hline MS does not homogeneously cause UEM & 13.320 & 0.252 & 0.801 & Zero causality \\
\hline UEM does not homogeneously cause MS & 8.196 & -0.528 & 0.598 & \\
\hline PR does not homogeneously cause UEM & 24.662 & 1.977 & $0.048 *$ & Unidirectional \\
\hline UEM does not homogeneously cause PR & 18.705 & 1.071 & 0.284 & causanty \\
\hline GDP does not homogeneously cause EXR & 13.595 & 0.293 & 0.769 & Zero causality \\
\hline EXR does not homogeneously cause GDP & 19.264 & 1.156 & 0.248 & \\
\hline MS does not homogeneously cause EXR & 19.809 & 1.239 & 0.215 & Zero causality \\
\hline EXR does not homogeneously cause MS & 7.941 & -0.567 & 0.571 & \\
\hline PR does not homogeneously cause EXR & 23.667 & 1.826 & $0.068 *$ & Unidirectional \\
\hline EXR does not homogeneously cause PR & 22.020 & 1.575 & 0.115 & causality \\
\hline MS does not homogeneously cause GDP & 9.720 & -0.296 & 0.768 & Zero causality \\
\hline GDP does not homogeneously cause MS & 8.609 & -0.465 & 0.642 & \\
\hline PR does not homogeneously cause GDP & 42.026 & 4.618 & $0.000 *$ & Unidirectional \\
\hline GDP does not homogeneously cause PR & 14.960 & 0.501 & 0.617 & causality \\
\hline PR does not homogeneously cause MS & 9.782 & -0.287 & 0.774 & Zero causality \\
\hline MS does not homogeneously cause PR & 7.956 & -0.564 & 0.573 & \\
\hline
\end{tabular}

Note: * represents 5 percent level of significance.

Table 3 indicates that evidence regarding feedback (unidirectional) association between the unemployment rate and inflation in the Dumitrescu Hurlin's test of causality. The finding in this study shows that Dumitrescu Hurlin Panel Causality test that considering two dimensions of heterogeneity in the panel set and taking in the coefficients to be different across cross-sections, one may find accuracy of estimation. 


\section{Concluding Remarks}

In the current study, the causal association between inflation and the unemployment in context of selected MENA countries was examined by employing annual panel data covering the period 1990-2016. To achieve this objective, the study used a panel Granger test of causality and Panel Dumitrescu and Hurlin causality test. The finding supports unidirectional causality between unemployment and inflation with Panel Dumitrescu and Hurlin Granger causality because of the superiority of the Dumitrescu Hurlin Panel Causality test that considering two dimensions of heterogeneity in the panel set and assumption of coefficients to be different across cross-sections. These findings are important for policy implications. If policy makers formulate policies to stabilize inflation, the country has to accept high unemployment rate. 


\section{References}

Abdulrahman, B. M. (2016). The relationship between unemployment and inflation in Sudan: An empirical analysis, 1992-2015. Research in Economics and Management, 1(2), 113.

Bildirici, M. \&. (2016). Non-linear analysis of Post Keynesian Phillips curve in Canada labor market. Procedia Economics and Finance, 38(2016), 368-377.

Cashell, B. W. (2004). Inflation and unemployment: What is the connection? Washington, DC: Congressional Research Service. Retrieved at:http://digitalcommons.ilr.cornell.edu/

Dritsaki, C. \&. (2013). Hysteresis in unemployment: An empirical research for three member states of the European Union. Theoretical \& Applied Economics, 20(4), 35-46.

Dumitrescu, E. I. (2012). Testing for Granger non-causality in heterogeneous panels. Economic Modelling, 29(4), 1450-1460.

Fischer, S. (1977). Long-term contracts, rational expectations, and the optimal money supply rule. Journal of Political Economy, 85(1), 191-205.

Furuoka, F., \& Munir, Q. (2014). Unemployment and inflation in Malaysia: Evidence from error correction model. Malaysian Journal of Business and Economics, 1(1), 35 - 45.

Furuoka, F. M. (2013). Does the Phillips curve exist in the Philippines? Economics Bulletin, 33(3), 2001-2016.

Granger, C. W. (1969). Investigating causal relations by econometric models and crossspectral methods. Econometrica: Journal of the Econometric Society, 37(3),424-438.

Granger, D. N. (1988). Role of xanthine oxidase and granulocytes in ischemia-reperfusion injury. American Journal of Physiology-Heart and Circulatory Physiology, 255(6), H1269-H1275.

Holtz-Eakin, D. N. (1988). Estimating vector autoregressions with panel data. Econometrica: Journal of the Econometric Society, 56(6),1371-1395.

Kogid, M. A. (2012). Inflation-Unemployment Trade-Off Relationship In Malaysia. Asian Journal of Business and Management Sciences, 1(1), 100-108.

Özer, M. Ö. (2016). The causal analysis of the relationship between inflation and output gap in Turkey. International Journal of Humanities and Social Science Invention, 5(11), $28-34$. 
Pakistan Journal of Humanities and Social Sciences, 6(1), 2018

Sa'idu, B. M. (2015). Do unemployment and inflation substantially affect economic growth? Journal of Economics, 3(2),132-139.

Siyan, P. A. (2016). Unemployment and inflation: Implication on poverty level in Nigeria. (No. 79765). MRPA. Available at https://mpra.ub.uni-muenchen.de/79765/.

Škare, M., \& Caporale, G. M. (2014). Short-and long-run linkages between employment growth, inflation and output growth: evidence from a large panel. Technological and Economic Development of Economy, 20(3), 554-575.

Umaru, A., \& Zubairu, A. A. (2012). Effect of inflation on the growth and development of the Nigerian economy (An Empirical Analysis). International Journal of Business and Social Science, 3(10),183-191.

Umoru, D., \& Anyiwe, M. A. (2013). Dynamics of inflationand unemployment in a vector error correction model. Research on Humanities and Social Sciences, 3(3), 20-29.

Vermeulen, C. (2015). Inflation, growth and employment in South Africa: Trends and tradeoffs. (No. 547). Economic Research Southern Africa.Available at: https://econrsa.org/system/

Yelwa, M. D. (2015). Analysis of the relationship between inflation, unemployment and economic growth in Nigeria: 1987-2012. Applied Economics and Finance, 2(3), 102109. 